\title{
Perspectives on the tensions in teaching with technology in Norwegian teacher education analysed using Argyris and Schön's theory of action
}

\author{
Steinar Thorvaldsen ${ }^{1}$ (D) $\cdot$ Siri Sollied Madsen ${ }^{1}$
}

Received: 14 February 2020 / Accepted: 6 May 2020 / Published online: 22 May 2020

(C) The Author(s) 2020

\begin{abstract}
Teachers' professional digital competence (PDC) is of increasing importance in classrooms in the majority of EU countries. Norway is one of the countries that has been exposed to a strong top-down implementation of information and communication technology in education. However, despite national efforts, practitioners in the education system do not seem to work in line with the given policy. There is therefore a gap between the micro and macro levels, necessitating the need for a closer exploration of the issue. We have conducted a quantitative study of teacher educators and their students in Northern Norway $(N=112)$. Amongst the staff, professional attitudes have a stronger impact than PDC regarding the extent of the educational use of digital tools, whereas amongst students, PDC has a stronger influence. These results are interpreted using Argyris and Schön's theory of action in learning organisations.
\end{abstract}

Keywords Teacher education · Digital attitude $\cdot$ Professional digital competence $\cdot$ Singleloop learning $\cdot$ Double-loop learning

\section{Introduction}

For many years, the use of information and communication technology (ICT) in education has been an important area of focus and discussion. In the majority of EU countries, the introduction of ICT in education has been incorporated into formal national guidelines on the degree requirements of teacher education as an official

Steinar Thorvaldsen

steinar.thorvaldsen@uit.no

Siri Sollied Madsen

siri.s.madsen@uit.no

1 Department of Education, UiT-The Arctic University of Norway, Tromsø, Norway 
policy. The US and its main teacher education accreditation organisations also push for the inclusion of technology in teacher education across the curriculum (Nelson et al. 2019).

Some countries have chosen a very offensive strategy in implementing this policy, and the ongoing changes and tensions in these contexts may be of special interest to study. In Norway, the modernisation of school curricula has resulted in several pervasive changes in school and pre-service teacher education. Digital competence (DC) was officially formulated in 2005 as the fifth basic skill for all subjects at all levels of school. Digital skills have a status equal to oral skills, reading, writing and numeracy. The government's White Paper No. 11 (Ministry of Education and Research 2008) has emphasised DC as one of the basic competencies that teacher educators and teacher students are required to focus on during their initial teacher education. Norway educate students in digital-rich environments, who have high access to various ICT and educational resources at home (Organisation for Economic Co-operation and Development [OECD] 2010, p. 95). This change in both the school curriculum and in the general plan for initial teacher education has, in effect, changed the underlying premise for teaching and learning in Norwegian teacher education programmes (Krumsvik 2014). In this case, in which the focus on DC has been exceptionally strong, some effects may be revealed clearly. This article studies the impact of such a pervasive strategy by presenting an exploration of teacher educators and their students at a Norwegian university (UiT, the Arctic University of Norway).

Does practice within teacher education correspond with the intentions of the national policy?

White paper No. 11 states that teachers has to integrate the use of digital media in their teaching practices, to ensure that the students education are covering the pupils needs in their digital lives. Still, several international studies show that teachers integrate technology insufficiently into their educational practices (Tondeur et al. 2012, 2016; Sancho-Gil et al. 2017). ICT has not changed education as much as anticipated by policy makers. Teacher education is constantly under criticism for disappointing outcomes. Several Norwegian studies have investigated how DC is integrated into teacher education (Lund et al. 2014; Instefjord and Munthe 2016; Gudmundsdottir and Hatlevik 2018). These studies report insufficient DC amongst teacher educators and that the use of digital tools in teacher education is less frequent and less developed than that in primary and secondary schools. Compared with the use of digital technology in our daily lives, teaching and learning with digital technology have not been so pervasive in teacher education. What is repeatedly observed in such surveys is that digital tools are not used satisfactorily compared to the formal goals related to them. A further conclusion is that academic staff do not have sufficient DC. Insufficient skills or interest amongst teacher educators may be a main obstacle to the integration of digital tools into educational practices. A lack of DC may be one explanation for the parsimonious educational practice, but are there also differences based on pedagogical theories, opinions and experiences?

Teacher education is of special interest, as it plays a double role in relation to technology - it develops both teacher students' professional skills and their expertise in facilitating pupils' learning. A teacher educator who uses digital tools for the enhancement of learning by students shows students at the same time how digital tools can be used in primary and secondary education (Drent and Meelissen 2008; Engen et al. 
2015). Creating good-quality teacher education in the digital arena has many facets, which take into account the needs of students, the school and the current curricula in order to prepare students for their future work as teachers.

In addition to teacher education, there has also been extensive research on the use of digital tools in general education in Norway, from primary to higher education. Looking at these surveys, we seem to move very slowly towards the described intentions regarding the use of digital tools. More importantly, there is a great gap between political intentions and what is done in practice in higher education (Norgesuniversitetet 2015; Tømte and Olsen 2013). Much of the mentioned research is focused on this gap, the use of digital tools in mainly supporting traditional teaching, and the potential for better utilising the opportunities embedded in technology. In these reports, the emphasis is on the professional reasons why teacher educators use digital tools in teaching, but the professional reasons for not using digital tools are hardly discussed.

For example, some recent research shows that students who often use computers or smartphones have a tendency to do worse compared with students who make less use of such tools in educational contexts (Beland and Murphy 2015; Carter et al. 2016; Elstad 2016b; Organisation for Economic Co-operation and Development [OECD] 2010). Mueller and Oppenheimer (2014) find that the use of laptops negatively affects students' test results. The authors' study focuses on students' use of a laptop instead of a pen when taking notes during lectures. They raise the question of whether using a laptop in classrooms does more harm than good. They also argue that note taking by hand calls for other cognitive processes compared with writing on a laptop. Elstad (2016b) writes that the general formational effect of education provides the requisite cognitive qualities for understanding. One can write faster on a laptop and take more notes. 'Although more notes are beneficial, at least to a point, if the notes are taken indiscriminately or by mindlessly transcribing content, as is more likely the case on a laptop than when notes are taken longhand, the benefit disappears' (Mueller and Oppenheimer 2014, 1166). To write by hand is slower, and one cannot take verbatim notes in the same way as with a laptop. Instead, students listen, digest and summarise so that they can succinctly capture the essence of the information. "Thus, taking notes by hand forces the brain to engage in some heavy "mental lifting," and these efforts foster comprehension and retention' (May 2014). As May points out, 'even when technology allows us to do more in less time, it does not always foster learning'.

On the other hand, a replication and extension of Mueller and Oppenheimer's experiment revealed only small and non-significant effects favouring note-taking by pen (Morehead et al. 2019). Hence, concluding which method is superior in improving the functions of note-taking seems premature. This underlines how important it is that the use of digital technology is targeted and that critical pedagogical assessments are paramount in different learning situations. Technology often changes the nature and meaning of tasks and activities, as well as creates new educational practices. Mixed findings on the impact of technology use on learner outcomes flag the need to rethink the way teachers are using technology to support learning (Fullan and Langworthy 2014). This underscores the need for a new analysis of the use of technologies in tackling twenty-first-century challenges.

Education is witnessing an ongoing demand for technology use in the classroom. However, research on teacher educators' level of professional digital competence (PDC) 
is limited, and the literature on teacher educators' competencies as role models is scarce (Valtonen et al. 2015; Uerz et al. 2018). New teacher students are entering the profession, and most of them, who were born in 1980 and later, are considered digital natives, whereas older teachers are labelled as digital immigrants (Prensky 2001). The years of birth of the generation of digital natives may differ according to various researchers, ranging from 1977 to 2002. Prensky describes digital natives as 'native speakers of technology, fluent in the digital language of computers, video games, and the Internet' (Prensky 2005, 8). He also emphasises that the digital native generation learns differently, both in K-12 classrooms and in higher education institutions. The native generation learns through experimentation, collaboration and peer-to-peer connection. By contrast, digital immigrants are immersed in an unfamiliar culture of technology use, language and behaviour. For the purpose of our study, Prensky's terms were applied, as these were used by several educational studies in recent years (Scherer 2011).

Robey et al. (2000) write that an increasing number of studies use organisational learning to understand the implementation and use of ICT in organisations. They claim that the main driver of this inquiry is the realisation that ICT frequently yields disappointing results. The authors further explain that a second emerging stream of research on ICT and organisational learning seeks to guide the application of technologies supporting organisational learning. Examining both the consequences of learning and the processes that produce these consequences, not either one or the other, is clearly valuable. More and more evidence recently points out that digital education policies are only successful if and where it has been possible to obtain teachers' participation, acceptance, engagement and ownership of the process (Foutsitzi and Caridakis 2019).

\section{Theoretical framework}

This study aims to contribute to the ongoing research on educational technology by applying theory of action by Argyris and Schön (1978) for a closer inspection of teacher education as performed at UiT in Northern Norway. Theory of action is widely used in organisational learning to describe the relationship of people in learning organisations. The descriptive framework serves as a methodological tool for the systematic analysis of learning organisations at the meso level (between the macro and micro levels). This approach begins by defining a concept of human beings as designers of action (Argyris 1992). The theory explains the mechanisms by which we link our thoughts with our actions. It is a theoretical framework which offers an analytical distinction between espoused theory and theory in use (Argyris and Schön 1996). This is used to structure and describe the data. Espoused theory is the theory of action framed to explain or justify a given pattern of activity. In other words, espoused theory can be understood as an individual's or organisation's attitudes towards practices. Theory in use is defined as the theory of action that is implicit in the performance of that pattern of activity, in other words, the practical action of competence. As described by Argyris and Schön $(1996,14)$, the organisational theory in use may be tacit rather than explicit. Tacit theories in use do not necessarily match the organisation's espoused theory. An organisation's formal documents, such as policy statements or work descriptions, will often contain espoused theories of action inconsistent with 
the organisation's actual pattern of activity (Argyris and Schön 1996). According to Argyris (1992, 216), these general theories of action determine all deliberate human behaviour. The mechanisms can occur both consciously and subconsciously; determining the discrepancy between the espoused theory and the theory in use may therefore be challenging.

\subsection{Theory in use (PDC)}

Within teacher education, DC has added complexities as opposed to other occupations or amongst average citizens (Krumsvik 2014). In the teaching profession, there are two dimensions to their DC. The first relates to their ability to use technology in a seamless way in order to encourage students to mirror this personal use. The second is pedagogical in its focus, as teacher educators must also simultaneously make pedagogic judgements which focus on how ICT can expand the learning possibilities for students in subjects. A theoretical approach was applied to construct statements for the questionnaire based on PDC. PDC in teacher education has been reviewed by Pettersson (2018). The term is a moving target in the sense that it evolves rapidly in line with the emergence of new technologies. The term was operationalised using the definitions by Tømte and Olsen (2013) and Lund et al. (2014). Based on their definitions, the focus was on three defined aspects of PDC: pedagogic and didactic understanding, subjectspecific understanding and technological understanding. This notion of digital competence also corresponds with the framework for teacher knowledge for technology integration called technological pedagogical content knowledge (TPACK), where there are three main components of teachers' knowledge: content, pedagogy, and technology (Koehler and Mishra 2009). The development of TPACK by teachers is internationally understood as critical for effective teaching with technology (Castéra et al. 2020; Tunjera and Chigona 2020). The definition of PDC was chosen because the literature is generally in agreement regarding this categorical understanding of PDC as consisting of three aspects (Lund et al. 2014; Pettersson 2018; Koehler and Mishra 2009).

\subsection{Espoused theory}

Statements were prepared based on the OECD report 'Connected Minds: Technology and Today's Learners' (2012) and its description of the field's existing attitudes towards technology in order to obtain an understanding of teacher educators' and students' professional attitudes (their espoused theories). In the paper, the field is characterised by a continuum from being technology averse to being technology positive. Statements were prepared to identify the respondents' own motivations for using digital tools, their attitudes towards digital tools' position in the public arena and their attitudes towards the use of digital tools in teaching.

\subsection{Professional application of tools}

This shows the extent to which the participants use digital tools and work methods in their teaching for the past year (i.e. the digital performance within the organisation). The construct consists of 16 single variables on digital tools/work methods applied in 
teaching during the past year. We also report scores for three general items related to this construct.

\subsection{Single-loop learning (SLL) and double-loop learning (DLL)}

A central and comprehensive theme in Argyris and Schön's learning theory is the link between learning, change and resistance to change. It outlines two models, namely single-loop learning processes (SLL, often called Model I) and double-loop learning processes (DLL or Model II), to highlight the potential for organisational learning. The models are illustrated in Fig. 1

SLL processes involve following the routines and some sort of pre-set plan which is both less risky for the individual and the organisation and affords greater control. It may also be characterised as a technical way of thinking. SLL seems to be present when goals, values, frameworks and strategies are taken for granted, with only minor updates. The emphasis is on techniques and making these more efficient. Any reflection is directed towards making the strategy more effective. In this paper, we link SLL with PDC.

DLL processes, by contrast, are more creative and reflexive, and they involve the consideration of notions about what is good. Reflection here is more fundamental. First, the basic assumptions behind ideas or policies are challenged and confronted. Second, hypotheses are publicly tested. Third, the processes are challenging, not self-seeking and have organisational goals. The governing aim includes valid information and internal commitment. DLL involves questioning the role of the framing and learning systems that underlie the actual goals and strategies (see Argyris and Schön 1978, 1996; Argyris 1992, 1996). We link DLL with professional attitudes.

In this study, we apply Argyris and Schön's (1996 xix) definition of a learning organisation as one with the 'ability to see things in new ways, gain new understandings, and produce new patterns of behaviours - all on a continuing basis and in a way that engages the organization as a whole'. Learning within teacher education is a dynamic process, not a prescriptive checklist of best practices (Argyris 2010). Argyris describes what he called SLL traps as patterns of values, behaviours and outcomes that 'make it difficult to produce the learning that is required to generate fundamental change' (Argyris 2010, 83). To be a learning organisation means to have a culture that

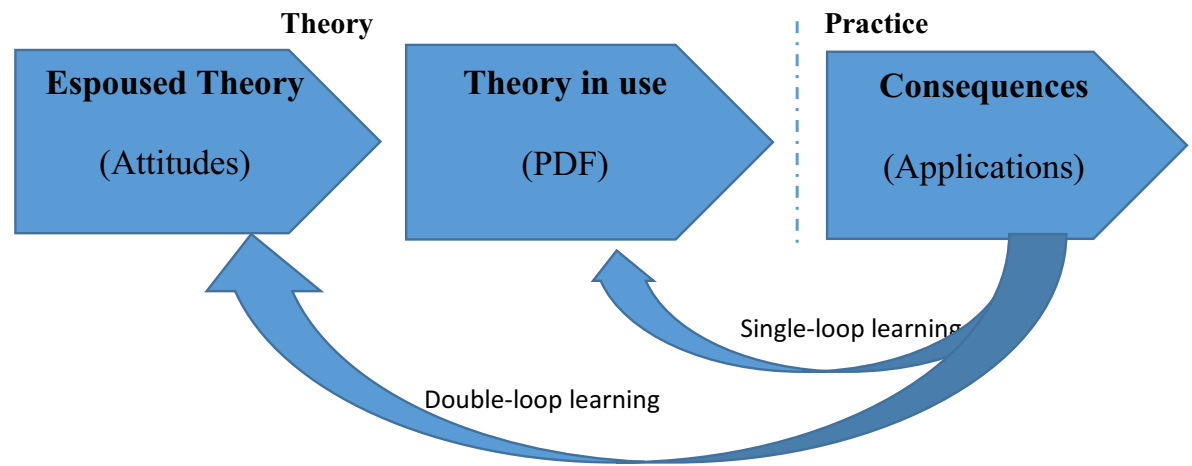

Fig. 1 Single-loop learning (SLL) and double-loop learning (DLL) processes. Adapted from Argyris and Schön (1978). Organizations that only stress SLL operate within a so-called SLL trap 
is centred upon DLL processes and to stay resilient against the SLL traps that may emerge in the organisation (Argyris 2010; Friesenborg 2015). When SLL traps are formed in a DLL organisation, a growing dissonance will manifest. Organisations with an emphasis on innovation learning are more likely to develop a culture of learning in SLL and DLL. The motivation in DLL has to be developed in line with the required pedagogy of the organisation.

\subsection{Research questions}

This study seeks to increase the understanding of how the technological revolution and its impact on education can be understood from a practitioner's point of view. It is a part of a research project aimed to elaborate further the complexity behind the observed mismatch between policies and the use of digital technology in teacher education. We explore the following two research questions:

(1) How do teacher educators and teacher students perceive their PDC, professional attitudes and professional application of tools in teaching?

We hypothesise that these variables may be substantially different amongst digital immigrants (teacher educators) compared with digital natives (teacher students).

(2) What is the relationship of SLL and DLL with digital performance in the learning processes of the organisation?

We hypothesise that there is no significant positive relationship of SLL and DLL with organisational learning performance amongst the respondents. The examination of causal relations is based on Argyris and Schön's theory of action.

\section{Research design}

We conducted a comparative study between teacher educators in Norway and teacher students in the fourth year of their master's program. The students were included to look for generational differences. The study utilised a quantitative approach to investigate the similarities and differences between these two groups of teachers, and it also examined the role of professional digital skills and attitudes in technology integration and practices in teaching.

The study was designed as a cross-sectional study starting with the academic staff in the Department of Education at UiT in spring 2015, with a follow-up of their students three years later to observe the influence of the educational process. Both academic staff and students were asked about the extent of their use of different digital technologies when teaching in order to obtain insights into the respondents' theories in use and actual practice. We conducted a survey of the academic staff in all teacher education programs at the Department of Education at UiT. This includes preschool teacher education, integrated master's in teacher education 1-7, integrated master's in teacher education 5-10, integrated master's in teacher education 8-13 and practical pedagogical education. Teachers from UiT presented a selection of 80 participants, among which 67 participants responded to a questionnaire survey. This implies a response rate of $83.8 \%$. We excluded all who were mainly administrative staff and employees who had less than $30 \%$ actual teaching in the past year. The data included in this survey are associated with the remaining 64 respondents. This group constitutes the target group, 
namely professional teacher education staff with $30 \%$ teaching or more. The student group included all fourth-year master's students in teacher education levels 1-7 and 510 , with 48 out of 61 students responding, indicating a response rate of $78.7 \%$.

There were $57.8 \%$ females amongst the staff and $66.7 \%$ amongst the students. The majority of the academic staff were above 45 years of age, whereas the majority of the students were 25 years or less (range: $23-31$ years). The young age of the students qualifies them to belong to the generation of digital natives (Prensky 2001).

\subsection{Instruments and statistical analysis}

The questionnaire was developed based on Argyris and Schön's theory of action. Data were collected from the teachers' and students' self-reports. The questionnaire had 38 items. A five-point Likert scale was used for most of the questions, as presented in the Appendix. Most items were collapsed into three multi-item constructs, whereas three items that were more general remained as single items (Table 2). The survey involves three main constructs: PDC, Professional Attitude and Professional Application of Tools.

The study was carried out digitally using the commercial online survey tool Questback. The questionnaire is a slightly modified version of the one used in our previous study (Madsen et al. 2018).

The statistical analysis of the quantitative data was carried out with SPSS Version 24 using descriptive statistics and t-tests for the comparison of the two independent groups. The constructs were tested for normality by the Kolmogorov-Smirnov test prior to statistical comparisons. We computed the Cronbach's alpha for all constructs as a measure of internal consistency and reliability. The Cronbach's alpha measures yielded an alpha value of 0.75 for PDC, 0.66 for Professional Attitude and 0.71 for Professional Application of Tools. These values described the extent to which all the items in the construct measured the same concept. The evaluation of the reliability of the data and the internal consistency in the three constructs created a basis for further analyses. We investigated the differences between the two groups by using the Student's t test, Pearson's correlations, and regression analysis. Cohen's effect size (d-value) was applied to examine the differences between the groups. This term calculates the difference between two groups measured in standard deviations and is estimated as the difference between the groups' averages divided by the average standard deviation for the two groups. King et al. (2011 246) refer to Cohen, who suggested that a power size of 0.2 represents a small effect, a coefficient of 0.5 is considered a moderate effect and 0.8 is considered to be a major effect. In Table 1, we first present the descriptive statistics describing the results for each individual question separately for the two groups, and then we show the results from the comparative tests between the groups and the effect size.

\section{Results}

The multi-item constructs in Table 1 show that the staff report somewhat higher PDC than the students do, but the difference is not significant. The staff score an average of 3.91, and the students score 3.74. It may not be surprising that teacher educators are 
Table 1 Self-perceived results from staff and students. The table also shows $p$ values (from the t-test) and effect sizes (Cohen's d)

\begin{tabular}{|c|c|c|c|c|c|}
\hline List of variables & Scale & $\begin{array}{l}\text { Staff } \\
\text { Mean (SD) }\end{array}$ & $\begin{array}{l}\text { Student } \\
\text { Mean (SD) }\end{array}$ & $\mathrm{p}$ value & Effect Size \\
\hline $\mathrm{PDC}(\mathrm{c})$ & $1-5$ & $3.91(.76)$ & $3.74(.66)$ & .20 & -.25 \\
\hline Professional Attitude (c) & $1-5$ & $3.00(.73)$ & $3.23(.54)$ & .056 & .38 \\
\hline Professional Application of Tools (c) & $1-5$ & $2.59(.54)$ & $2.88(.41)$ & $.002 * *$ & .60 \\
\hline I often use digital tools in my own teaching. & $1,2,3,4,5$ & $3.95(1.09)$ & $4.50(.77)$ & $.002 * *$ & .59 \\
\hline $\begin{array}{l}\text { I mainly use digital tools in my teaching } \\
\text { because it is expected by others. }\end{array}$ & --- “--- & $1.88(1.06)$ & $2.31(.99)$ & $.029 *$ & .43 \\
\hline $\begin{array}{l}\text { I have experienced that the use of technology } \\
\text { in teaching has been disruptive for the } \\
\text { expected outcomes. }\end{array}$ & --- “--- & $2.83(1.12)$ & $2.98(1.06)$ & .47 & .14 \\
\hline
\end{tabular}

$N=112$. (c) Constructs combining single variables as shown in the Appendix.* Significant at the 0.05 level (2tailed). ** Significant at the 0.01 level (2-tailed)

somewhat more familiar with digital learning tools in education and that they are more confident in using them. This is about accumulated technological and pedagogical experience.

In terms of attitudes, students are less critical than teacher educators ( $p$ value $=$ 0.056). On average, however, both groups are reasonably neutral in terms of whether they consider digital technology important for good teaching. When asked if there is an exaggerated belief in digital technology in teaching, academic staff respond that from both a societal and a university perspective, there exists an exaggerated belief in the effects of digital technology. Of the staff respondents, only $16 \%$ disagree with the statement 'Society's expectations of the impact of digital tools are exaggerated', whereas $58 \%$ of the staff moderately or strongly agree with the statement. Therefore, societal expectations are not necessarily in line with teacher educators' espoused theories.

Table 1 likewise presents the results for the application of digital tools and work methods in teaching during the past year. The construct Professional Application of Tools consists of 16 items, and six of these (multiple choice, production of video, production of wikis, student response systems, collaborative writing [e.g. Google Docs] and the Internet as a source of knowledge) show a significantly higher use ( $p$ value $<0.05$ ) in the student group. The staff group scored significantly higher in three items (Moodle or Fronter, digital presentations and online meetings). The construct Professional Application of Tools has a significantly higher score for the students ( $p$ value $=$ 0.002 ), and they agree to a larger extent than the staff that digital tools are used because this usage is expected by others ( $p$ value $=0.029$ ). The different scores in application could be explained by the fact that the staff relate mainly to teaching in higher education, whereas the students relate more to education in primary and secondary schools.

As shown in Table 2, there is a significant and quite high positive relationship of both PDC and Professional Attitude with Professional Application of Tools. In terms of Argyris and Schön's theory, SLL and DLL have a relation to organisational learning performance. The correlation analyses conducted for each group also revealed 
Table 2 Correlations for each group separately

\begin{tabular}{lll}
\hline & PDC (c) & Professional attitude (c) \\
\hline Professional Application of Tools (c) & $.327 * *$ (Staff) & $.452 * * *$ (Staff) \\
& $.428^{* *}$ (Students) & $.327 *$ (Students) \\
\hline
\end{tabular}

$\mathrm{N}=112$. (c) Construct combining single variables. * Significant at the 0.05 level (2-tailed). ** Significant at the 0.01 level (2-tailed). *** Significant at the 0.001 level (2-tailed)

interesting differences (Table 2). Amongst the staff, the Professional Application of Tools variable is strongly correlated with Professional Attitude $(r=.452)$ and less with PDC $(r=.337)$, but in the student group, it is the other way around.

When we try to predict the outcome of the professional application of digital tools (Professional Application of Tools) amongst the students, the best predictor is PDC $($ Beta $=.371, p$ value $=.008)$, whereas the best predictor for staff is Professional Attitude $($ Beta $=.382, \mathrm{p}$ value $=.003)$. It appears from this analysis that the contribution related to digital practice occurs quite differently between the two groups. Amongst the academic staff, the professional use or application of digital tools is dominated by Professional Attitude, whereas amongst the student group, it is dominated by PDC. At the same time, PDC is somewhat lower in the student group, but Professional Application of Tools is significantly higher. The adjusted R-square for the multiple regression model in Table 3 is .20 for both groups, which tells us that $20 \%$ of the variation in the output variable (Professional Application of Tools) can be explained by the predictors in the model. Although several factors are outside our regression model (e.g. academic level, subject), our hypothesis that there is no significant positive relationship of SLL and DLL with organisational learning performance is rejected.

\section{Discussion}

As mentioned earlier, teacher education is often described as being one step behind primary and secondary schools in the use of digital tools, and the confidence in teacher education to handle this gap has been weak (Haugsbakk 2013; Selwyn 2016). Elstad (2016a) claims that young people have digital capabilities and that some researchers regard them as digital natives, in contrast to teachers who are disrespectfully described as digital slow coaches (Elstad 2006) or digital immigrants (Prensky 2001). However, in our study, the staff in the Department of Education report slightly higher scores in

Table 3 Regression analysis with Professional Application of Tools as the outcome

\begin{tabular}{llllll}
\hline List of Variables & \multicolumn{2}{l}{ Staff } & & \multicolumn{2}{l}{ Students } \\
\cline { 2 - 3 } & Beta (standardised) & $\mathrm{p}$ value & & Beta (standardised) & $\mathrm{p}$ value \\
\cline { 2 - 5 } & .175 & .16 & & .371 & $.008^{* * *}$ \\
PDC & .382 & $.003^{* *}$ & .239 & .08 \\
\hline
\end{tabular}

**Significant at the 0.01 level (2-tailed) 
PDC than do the teacher students at grade 4. In a study of over 2000 preservice teachers, Guo et al. $(2008,251)$ also find no statistically significant difference between digital natives and digital immigrants with regard to ICT. It seems that the differences between staff and students are not mainly related to being digital immigrant or digital native. The difference is to a greater degree connected to the complex competence gained through professional practice, regarding the complex interaction of both content knowledge, pedagogical knowledge and technological knowledge.

Technology in itself is often seen as a catalyst for educational change, and technology as a symbol for change is often understood as something positive, as investments in technology will support development in society. Haugsbakk (2013) argues that this reflects an instrumental perspective on technology. There are also situations in which the use of technology may not lead to better learning outcomes or increased efficiency (Elstad 2016a, 2016b; Selwyn 2016). Knowledge of technology is only one critical component of teachers' use of technology in their practice; they also need to know how to use it for successful integration in teaching and student learning.

As we have seen, most teacher educators do not agree with the signals that are communicated in public. What is more surprising is that the same trend is applicable when asked if there are excessive expectations of the effect of digital tools in the academic debates at the university. On this question, only $13 \%$ of the staff answer that they somewhat or completely disagree that the UiT's academic debates have exaggerated expectations of the effects of digital tools. However, $50 \%$ agree that the academic debates at UiT are characterised by too high expectations of the effect of digital tools.

These figures represent a bias characterised by a dual culture, one in which employees have an attitude towards digital tools indicating that the majority within the teacher training staff do not consider digital tools essential for good teaching. This suggests an inner academic culture that does not correspond with the public culture and with general university policies, or that the employees' attitudes are quite diverse, and the staff are possibly a fragmented and inconsistent group. However, the fact that most of the academic staff in the Department of Education think that the academic debates at the university are characterised by too much confidence in digital tools can also indicate several other things. For example, in debates, employees express more optimism towards digital tools in teaching than they really mean. It may concern political correctness and a desire not to go against the flow. Another explanation might be that those who dominate the debates are the technologically positive ones, whereas those who are critical choose not to express themselves.

The figures from the students are more in line with the public culture and with the expressed university policies. One interpretation may be that the teacher students do not have the amount of experience that the teacher staff have in terms of experiencing the limitations and negative effects of digital technology. The students could be more optimistic and influenced by how digital technology is introduced, and not so much by how it is experienced, as they have narrower experiences compared with the teacher educators. The latters' experience and legitimacy through a long career could make it easier for them to go against the flow and to adopt independent attitudes when they disagree with a certain educational policy. This is supported by some differences in the answers to the questions about whether the respondents use digital technology because it is expected by others (Table 2), in which the students agree significantly more than the staff do $(p$ value $=.029$, with effect size $d=.43)$. 
In our regression analysis, we found that the contribution to digital practice occurs somewhat differently between the academic staff and the student group. For the staff, their digital practice is dominated by Professional Attitude, whereas in the student group, it is dominated by PDC. Argyris and Schön's theory of action may give us a relevant framework to understand this observation on a deeper conceptual level. The theory emphasises SLL and DLL learning processes. From our analysis above, we infer that the students' didactical perspective may be characterised as somewhat dominated by SLL processes based on PDC, whereas the academic staff are also strongly involved in DLL processes in which their professional attitudes are involved. The interactions are illustrated in Fig. 1. SLL is effective and rational at the basic didactical level, whereas DLL models are more open to discussions and adaptations and provide more opportunities for choice. With experience, the academic staff look for new methods when the SLL results in a mismatch between educational goals and the achieved goals. When entering a DLL process and looking critically into the preconditions for the challenges at hand, the teachers enter a systemic double loop.

Farjon et al. (2019) conducted a study at a large Dutch university to examine the extent to which teacher students integrate digital technology into their own practice. They find that attitudes have the greatest effect on students' use of digital technology in their own practice, measured against experience, DC and access to digital tools. However, only pre-service teachers at the very start of their initial teacher education program were included in the Dutch study, whereas the students in our study are in their fourth year, so the findings cannot be compared directly.

According to Elstad (2016c), political expectations regarding the modernisation of the schooling system using ICT and the allocation of funds in accordance with this policy created agendas that are not compatible with the constraints and operational features within education. If one is presented with an ideology and this guides practice, the students are more likely to act based on SLL. With experience comes a greater opportunity to evaluate not only policy but also how policy affects practice. This knowledge is a prerequisite for making a critical analysis of teaching and for acting based on DLL.

To be a learning organisation means to have a culture that involves DLL processes and to remain resilient against the SLL traps that may emerge in the organisation and create tension and dissonance (Argyris 2010). Because SLL is prevalent in the dominant culture (Edmondson 1996), learning organisations such as those involved in teacher training may be susceptible to SLL traps that develop from the dominant societal culture. We interpret the observed tensions on the use of ICT within teacher education as the emergence of such SLL traps.

In DLL processes, an educational organisation can handle the basic challenges related to the application of new technology. It is not about being one step behind but about taking steps aside to gain a deeper perspective. Successful teaching is not only about finding the right technology but also about adding the values, norms and attitudes that reside within the academic staff in teacher training organisations.

Langset et al. (2018) find that contrary to top-down initiatives, a more horizontal approach supports the pedagogical variation and tailor-made solutions that are necessary in large heterogeneous organisations. The project conducted by Langset et al. (2018) focused on local initiative and participation, as well as the feeling of autonomy that the participants experienced. The participants were free to explore new applications 
at their own pace and to decide on which new technologies to implement and how to use them in their courses. The findings in their study showed that these were important factors supporting the argument for horizontal approaches instead of top-down implementation.

In a recent analysis of curriculum documents for teacher education in Norway, Instefjord and Munthe (2016) point out that DC and the use of digital technology are not integrated to a satisfactory degree at the subject-specific level, and this is still work in progress. Plans will need tight coupling based on experience to have a successful learning impact. Subject-based didactics should, to a greater extent, set the terms for technology in education, not the other way around.

This calls for education institutions as professional learning organisations, with communities of school practitioners engaged in an ongoing dialogue to promote development and reflection cycles in students and teachers.

\subsection{Limitations of the study}

The limitations of this study were as follows:

1. Single university: The sample size for this study was limited because it involved only one Norwegian university. Hence, the sample can be described as a university case. This limits full generalisation of the findings to other regions and countries. The sample does not allow drawing strong conclusions on the national or international macro scale (educational policies).

2. The constructs in this study are based on teachers' self-ratings. To further address and validate the observations, we conducted interviews with the academic staff to be published in a separate qualitative study.

3. As we mentioned, the term 'PDC' evolves rapidly as a moving target. Our operationalisation of the concept may be extended. Recent research (Caena and Redecker 2019; McGarr and McDonagh 2019) underpins a broader understanding of PDC by including professional engagement, collaborative learning, source criticism, responsible use, creation and managing with ICT.

\section{Concluding remarks}

Our aim was to study a university department as a learning organisation. Many EU governments have been active in influencing and reforming both the school system and teacher education. The Norwegian implementation plan positions digital technology in teaching in a way that activates resistance and creates contrasts between teacher educators' experiences and work-related requirements for implementation. This paper presents findings regarding how this affects teacher educators' and students' attitudes towards their professional position.

The political enthusiasm that has prevailed in the field is, to a greater extent, now met with critical reflections. Ranking policy goals above pedagogical goals in this field is largely contrary to teachers' understanding of teacher proficiency. The observation that digital tools are not successfully integrated into teacher education can be related to the optimistic expectations towards the use of digital technology in our society (PlayerKoro 2013; Macgilchrist 2019). We need to critically examine this technological 
optimism, which has promoted a somewhat unrealistic view of the ability of digital tools in education.

It is too easy to hold teacher education as the main factor responsible for the lack of successful integration of digital tools into learning practices. The limited digital success suggests that these efforts to update and improve teacher education might not be a quick way forward to closing the observed gap. The digital tools themselves and their actual value in various learning environments seem to need a deeper examination, as the value of technology should not be taken for granted in the domain of education. Technology integration into the pedagogical landscape is complicated. As an alternative to top-down initiatives, we recommend a more horizontal approach that facilitates teacher educators' autonomy and ideas for new ways of doing things (Langset et al. 2018). By this, one may envision an interesting turning point associated with digital technology in the education system.

In this study, we used a self-designed questionnaire encompassing Argyris and Schön's SLL and DLL, tied directly to the pedagogical application of digital tools. The correlation and regression were used to analyse the influence of the skills (PDC) and attitudes (mindsets and opinions) of the respondents on the pedagogical applications (practice) within the organisation.

We asked how teacher educators and teacher students perceive the professional use of digital tools and compared their perceptions. In this study, we made several observations. Norwegian teacher trainers and their master's students both report similar levels of PDC, but the teacher trainers have a more critical attitude than their students towards the application of digital technology in education. Extended experience may explain why the academic staff have a different viewpoint on the pedagogical use of digital tools. Mere skills and knowledge are not enough to integrate technology successfully (Mouza et al. 2014). SLL is only a legitimate requirement if the organisation is to develop DLL in order to achieve high system performance in a complex pedagogical landscape. Correlation and multiple linear regression were used to understand the relationships and contributions of SLL and DLL to organisational learning performance. The investigation empirically identified the potential for the development of an SLL and DLL culture to foster positive contributions to organisational learning performance.

We found that Argyris and Schön's differentiation between SLL and DLL in their theory of action may contribute to a deeper acknowledgement of the fundamental challenges that need to be settled in the domain of educational technology. Both processes exist at the same time and may have different actors. Both actors are important and may make valuable contributions to refining the learning process when technology is involved. However, a legitimate system (SLL) is not enough and may contribute to creating the observed dissonance (SLL trap). Teacher education requires adaptable and functional team thinking (DLL) to develop a realistic vision and share knowledge.

Our results show that both staff and students within teacher education are aware of the need for developing both SLL and DLL to achieve the required processes of learning for performance concerning educational technology. Earlier research has made a point to distinguish between digital natives and digital immigrants, but we 'need to get beyond calling teachers digital immigrants, as if technology holds a certain code [that] only young people can decipher' (Interview with Karen Cator, see Scherer 2011; Bennett et al. 2008). Teacher educators have developed awareness regarding how digital technology can be integrated into the curricula and the kinds of strategies that 
are best suited to help pre-service teacher students obtain this knowledge for their future work. The present study may contribute to increasing such awareness whilst simultaneously clarifying the content and the complicated processes of technology integration in teaching and learning.

Faster, better, cheaper, when applied to education, is not a productive concept. It is a false economy, as it is very difficult to have all three simultaneously. With educational technology, the terms 'well-founded' and 'sustainable' are better. Argyris and Schön's emphasis on both SLL and DLL adds new perspectives to a deeper understanding of the ongoing process of developing a sustainable use of technologically within educational institutions.

Acknowledgements A preliminary version of this paper was presented at OOFHEC2018: the Online, Open and Flexible Higher Education Conference in Aarhus, Denmark.

Funding information Open Access funding provided by UiT The Arctic University of Norway.

\section{Appendix}

The survey in this study involves three main constructs: Professional Digital Competence, Professional Attitude and Professional Application of Tools. Professional Digital Professional Competence and Professional Attitude were measured on five-point Likert-scaled statements with the following scoring options: $1=$ strongly disagree, $2=$ moderately disagree, $3=$ neutral, $4=$ moderately agree and $5=$ strongly agree. Professional Application of Tools was measured based on the reported frequency of use of 16 digital technologies and work methods of the participants in their own teaching in the past year, with $1=$ never, $2=$ rarely, $3=$ occasionally, $4=$ often and $5=$ extensively. Some items had a reversed scale, denoted by REV (reversal). The constructs were each based on the following questionnaire items:

Professional Digital Competence (PDC):

- I am familiar with the digital tools that can help diversify teaching.

- I am, in general, confident when using digital tools.

- I find it easy to become familiar with new digital tools.

- I can use digital tools that are appropriate for the aspects of the subjects I am teaching.

- It is difficult to use digital tools as educational resources within my subject. REV.

Professional Attitude:

- When I use digital tools in my teaching, I find that they add value.

- The use of digital tools is essential for good teaching.

- Society's expectations of the impact of digital tools are exaggerated. REV.

- Expectations related to the use of digital tools in teaching frustrate me. REV.

- In academic debates at our university, the expectations of the impact of digital tools are exaggerated. REV. 
Professional Application of Tools:

- Digital tools for testing with multiple choice questions

- Moodle or Fronter (each university's learning management system)

- Digital tools for presentation (e.g. PowerPoint or Prezi)

- Word processor

- Spreadsheets (e.g. Excel)

- Use of video

- Production of film/video/animation

- Online discussions

- Online meetings (e.g. Lync, Adobe Connect or Skype)

- Production of Wiki (website that allows collaborative modification)

- Screen capture (e.g. Camtasia or Mediasite)

- Programs for scientific analyses

- Student response systems (online questions answered by phone or computers, such as Kahoot! or Socrative)

- Tools for collaborative writing (e.g. Google Docs)

- Social media (e.g. Facebook or Twitter)

- The Internet as a source of knowledge

Open Access This article is licensed under a Creative Commons Attribution 4.0 International License, which permits use, sharing, adaptation, distribution and reproduction in any medium or format, as long as you give appropriate credit to the original author(s) and the source, provide a link to the Creative Commons licence, and indicate if changes were made. The images or other third party material in this article are included in the article's Creative Commons licence, unless indicated otherwise in a credit line to the material. If material is not included in the article's Creative Commons licence and your intended use is not permitted by statutory regulation or exceeds the permitted use, you will need to obtain permission directly from the copyright holder. To view a copy of this licence, visit http://creativecommons.org/licenses/by/4.0/.

\section{References}

Argyris, C. (1992). On organizational learning. Cambridge, Massachusetts: Blackwell Publisher.

Argyris, C. (1996). Unrecognized defenses of scholars: Impact on theory and research. Organization Science, 7(1), 79-87. https://doi.org/10.1287/orsc.7.1.79.

Argyris, C. (2010). Organizational traps: Leadership, culture, organizational design. New York, NY: Oxford University Press.

Argyris, C., \& Schön, D. A. (1978). Organizational learning: A theory of action perspective. Reading, Mass: Addison-Wesley.

Argyris, C., \& Schön, D. A. (1996). Organizational learning II. Theory, method, and practice. Reading, Mass: Addison-Wesley.

Beland, L.-P., \& Murphy, R. (2015). III communication: Technology, Distraction \& Student Performance. In Centre for Economic Performance, discussion paper no 1350. Centre for: Economic Performance, London School of Economics and Political Science, London.

Bennett, S., Maton, K., \& Kervin, L. (2008). The 'digital natives' debate: A critical review of the evidence. British Journal of Educational Technology, 39(5), 775-786.

Caena, F., \& Redecker, C. (2019). Aligning teacher competence frameworks to 21 st century challenges: The case for the European digital competence framework for educators (Digcompedu). European Journal of Education, 54(3), 356-369. 
Carter, S.P., K. Greenberg, and M. Walker. 2016. "The Impact of Computer Usage on Academic Performance: Evidence from a Randomized Trial at the United States Military Academy. Working Paper \#2016.02." . https://seii.mit.edu/wp-content/uploads/2016/05/SEII-Discussion-Paper-2016.02Payne-Carter-Greenberg-and-Walker-2.pdf

Castéra, J., Marre, C. C., Yok, M. C. K., Sherab, K., Impedovo, M. A., Sarapuu, T., Pedregosa, A. D., Malik, S. K., \& Armand, H. (2020). Self-reported TPACK of teacher educators across six countries in Asia and Europe. Education and Information Technologies. https://doi.org/10.1007/s10639-020-10106-6.

Drent, M., \& Meelissen, M. (2008). Which factors obstruct or stimulate teacher educators to use ICT innovatively? Computers \& Education, 551(1), 187-199.

Edmondson, A. C. (1996). Three faces of Eden: The persistence of competing theories and multiple diagnoses in organizational intervention research. Human Relations, 49(5), 571-595.

Elstad, E. (2006). Understanding the nature of accountability failure in a technology-filled, laissez-faire classroom: Disaffected students and teachers who give in. Journal of Curriculum Studies, 38(4), 459-481.

Elstad, E. (2016a). Educational technology - expectations and experiences: An introductory overview. In E. Elstad (Ed.), Digital expectations and experiences in education (pp. 3-28). Rotterdam: Sense Publishers.

Elstad, E. 2016b. "Introduction." In Digital Expectations and Experiences in Education, edited by E. Elstad, VII-X. Rotterdam: Sense Publishers.

Elstad, E. (2016c). Why is there a wedge between the promise of educational technology and the experiences in a technology-rich Pioneer School? In E. Elstad (Ed.), Digital expectations and experiences in education (pp. 77-96). Rotterdam: Sense Publisher.

Engen, B. K., Giæver, T. H., \& Mifsud, L. (2015). Guidelines and regulations for teaching digital competence in schools and teacher education: A weak link? Nordic Journal of Digital Literacy, 10(2), 69-83.

Farjon, D., Smits, A., \& Voogt, J. (2019). Technology integration of pre-service teachers explained by attitudes and beliefs, competency, access, and experience. Computers \& Education, 130(March 2019), 81-93. https://doi.org/10.1016/j.compedu.2018.11.010.

Foutsitzi, S., \& Caridakis, G. (2019). ICT in education: Benefits, challenges and new directions. In 10th international conference on information. Intelligence, Systems and Applications (IISA), Patras: Greece. https://doi.org/10.1109/IISA.2019.8900666.

Friesenborg, L. (2015). The culture of learning organizations: Understanding Argyris' theory through a sociocognitive systems learning model. Iowa: Brennan-Mitchell Publishing Group.

Fullan, M., \& Langworthy, M. (2014). A rich seam. How pedagogies find deep learning. London, UK: Pearson.

Gudmundsdottir, G. B., \& Hatlevik, O. E. (2018). Newly qualified teachers' professional digital competence: Implications for teacher education. European Journal of Teacher Education, 41(2), 214-231. https://doi. org/10.1080/02619768.2017.1416085.

Guo, R. X., Dobson, T., \& Petrina, S. (2008). Digital natives, digital immigrants: An analysis of age and ICT competency in teacher education. Journal of Educational Computing Research, 38(3), 235-254. https://doi.org/10.2190/EC.38.3.a.

Haugsbakk, G. (2013). From sputnik to PISA shock - new technology and educational reform in Norway and Sweden. Education Inquiry, 4(4), 607-628.

Instefjord, E., \& Munthe, E. (2016). Preparing pre-service teachers to integrate technology: An analysis of the emphasis on digital competence in teacher education curricula. European Journal of Teacher Education, 39(1), 77-93. https://doi.org/10.1080/02619768.2015.1100602.

King, B. M., Rosopa, P. J., \& Minium, E. W. (2011). Statistical reasoning in the behavioral sciences (6th ed.). New York: Wiley.

Koehler, M., \& Mishra, P. (2009). What is technological pedagogical content knowledge? Contemporary Issues in Technology and Teacher Education, 9(1), 60-70.

Krumsvik, R. J. (2014). Teacher educators' digital competence. Scandinavian Journal of Educational Research, 58(3), 269-280. https://doi.org/10.1080/00313831.2012.726273.

Langset, I. D., Jacobsen, D. Y., \& Haugsbakken, H. (2018). Digital professional development: Towards a collaborative learning approach for taking higher education into the digitalized age. Nordic Journal of Digital Literacy, 13(1), 24-39.

Lund, A., Furberg, A., Bakken, J., \& Engelien, K. L. (2014). What does professional digital competence mean in teacher education? Nordic Journal of Digital Literacy, 9(4), 281-299.

Macgilchrist, F. 2019. Cruel optimism in Edtech: When the digital data practices of educational technology providers inadvertently hinder educational equity" Learning, Media and Technology 44 (1): 77-86. doi: https://doi.org/10.1080/17439884.2018.1556217. 
Madsen, S.S., S. Thorvaldsen, and S. Archard. 2018. "Teacher Educators' Perceptions of Working with Digital Technologies.” Nordic Journal of Digital Literacy 13 (3): 177-196. https://doi.org /https://doi. org/10.18261/issn.1891-943x-2018-03-04.

May, C. 2014. “A Learning Secret: Don’t Take Notes with a Laptop.” Accessed February 8, 2020 https://www.scientificamerican.com/article/a-learning-secret-don-t-take-notes-with-a-laptop/.

McGarr, O., and A. McDonagh. 2019. "Digital Competence in Teacher Education. Output 1 of the Erasmus+ Funded Developing Student Teachers' Digital Competence (DICTE) Project.” Accessed December 13, $2019 \mathrm{https}$ ://dicte.oslomet.no/.

Ministry of Education and Research 2008. "Stortingsmelding nr. 11, Læreren, rollen og utdanningen." Accessed May 13, 2019 https:/www.regjeringen.no/no/dokumenter/stmeld-nr-11-2008-2009-/id544920/.

Morehead, M., Dunlosky, J., \& Rawson, K. A. (2019). How much mightier is the pen than the keyboard for note-taking? A replication and extension of Mueller and Oppenheimer 2014. Educational Psychology Review, 31, 753-780. https://doi.org/10.1007/s10648-019-09468-2.

Mouza, C., Karchmer-Klein, R., Nandakumar, R., \& Yilmaz Ozden, S. (2014). Investigating the impact of an integrated approach to the development of Preservice teachers' technological pedagogical content knowledge (TPACK). Computers \& Education, 71(2), 206-221. https://doi.org/10.1016/j. compedu.2013.09.020.

Mueller, P. A., \& Oppenheimer, D. M. (2014). The pen is mightier than the keyboard: Advantages of longhand over laptop note taking. Psychological Science, 25(6), 1159-1168.

Nelson, M. J., Voithofer, R., \& Cheng, S. L. (2019). Mediating factors that influence the technology integration practices of teacher educators. Computers \& Education, 128(January 2019), 330-344. https://doi.org/10.1016/j.compedu.2018.09.023.

Norgesuniversitetet. (2015). Digital tilstand 2014 (Vol. 1). Norgesuniversitetet.

Organisation for Economic Co-operation and Development. (2010). "Are Students Ready for a Technologyrich World? What PISA Studies Tell Us." Accessed May 13, 2019 https://www.oecd. org/education/school/programmeforinternationalstudentassessmentpisa/35995145.pdf.

Organisation for Economic Co-operation and Development. (2012). "Connected Minds. Technology and Today's Learners. Educational Research and Innovation.” Accessed May 13, 2019 https://www.oecdilibrary.org/docserver/9789264111011-en.pdf.

Pettersson, F. (2018). On the issues of digital competence in educational contexts-a review of literature. Education and Information Technologies, 23(3), 1005-1021.

Player-Koro, C. (2013). Hype, Hope and ICT in teacher education: A Bernsteinian perspective. Learning, Media and Technology, 38(1), 26-40.

Prensky, M. (2001). Digital natives, digital immigrants. On the Horizon, 9(5), 1-6. https://doi.org/10.1108 /10748120110424816.

Prensky, M. (2005). Listen to the natives. Educational Leadership, 63(4), 8-13.

Robey, D., Boudreau, M. C., \& Rose, G. M. (2000). Information technology and organizational learning: A review and assessment of research. Accounting, Management and Information Technologies, 10(2), 125155. https://doi.org/10.1016/S0959-8022(99)00017-X.

Sancho-Gil, J. M., Sánchez-Valero, J. A., \& Domingo-Coscollola, M. (2017). Research-based insights on initial teacher education in Spain. European Journal of Teacher Education, 40(3), 310-325. https://doi. org/10.1080/02619768.2017.1320388.

Scherer, M. (2011). Transforming education with technology: A conversation with Karen Cator. Educational Leadership, 68(5), 16-21.

Selwyn, N. (2016). Minding our language: Why education and technology is full of bullshit ... and what can be done about it. Learning, Media \& Technology 41 (3): 437-443. https://doi.org/10.1080 /17439884.2015.1012523, .

Tømte, C., and D.S. Olsen. 2013. "IKT og læring i høyere utdanning. NIFU Rapport 32/2013.” . http://osloedtech.no/wp-content/uploads/2016/03/NIFUrapport2013-32.pdf.

Tondeur, J., van Braak, J., Sang, G., Voogt, J., Fisser, P., \& Ottenbreit-Leftwich, A. (2012). Preparing preservice teachers to integrate Technology in Education: A synthesis of qualitative evidence. Computers \& Education, 59, 134-144. https://doi.org/10.1016/j.compedu.2011.10.009.

Tondeur, J., van Braak, J., Tondeur, J., Siddiq, F., \& Scherer, R. (2016). Time for a new approach to prepare future teachers for educational technology use: Its meaning and measurement. Computers \& Education, 94, 134-150. https://doi.org/10.1016/j.compedu.2015.11.009.

Tunjera, N., \& Chigona, A. (2020). Teacher Educators' appropriation of TPACK-SAMR models for 21st century pre-service teacher preparation. International Journal of Information and Communication Technology Education (IJICTE), 16(3), 1-15. https://doi.org/10.4018/IJICTE.2020070110. 
Uerz, D., Volman, M., \& Kral, M. (2018). Teacher educators' competences in fostering student teachers' proficiency in teaching and learning with technology: An overview of relevant research literature. Teaching and Teacher Education, 70, 12-23. https://doi.org/10.1016/j.tate.2017.11.005.

Valtonen, T., Kukkonen, J., Kontkanen, S., Sormunen, K., Dillon, P., \& Sointu, E. (2015). The impact of authentic learning experiences with ICT on pre-service teachers' intentions to use ICT for teaching and learning. Computers \& Education, 81, 49-58. https://doi.org/10.1016/j.compedu.2014.09.008.

Publisher's note Springer Nature remains neutral with regard to jurisdictional claims in published maps and institutional affiliations. 